\title{
The study of formulation and performance of formate drilling and completion fluid system
}

\author{
Bingren Wang ${ }^{1}$, Zehua Wang $^{2 *}$, Yuxue Sun ${ }^{2}$, Jiuzhou Sun $^{1}$ \\ ${ }^{1}$ Northeast Petroleum University, Daqing, China \\ ${ }^{2}$ Reservoir Protection Laboratory, Northeast Petroleum University, Daqing, China; \\ *Corresponding Author: wangzehua0000@,163.com
}

Received 21 June 2013; revised 21 July 2013; accepted 28 July 2013

Copyright (C) 2013 Bingren Wang et al. This is an open access article distributed under the Creative Commons Attribution License, which permits unrestricted use, distribution, and reproduction in any medium, provided the original work is properly cited.

\begin{abstract}
Formate drilling and completion fluid system is a new type of clean organic salt brine system which has been developed from inorganic salt brine drilling fluid system. It is beneficial to protecte and find hydrocarbon reservoir. Due to the solid free system, the damage of solid phase particles on reservoir, especially low permeability oil and gas layer, can be greatly eliminated, at the same time, drilling fluid and completion fluid have greater compatibility. It will avoid that precipitation which is not compatible with drilling and completion fluid and generates damages on reservoir. And because mud cake of the solid free system is thin and resilient, it is conductive to improve cementing quality greatly. Experiments show that the formate drilling and completion system has good rheological property, strong inhibition ability, good lubricating performance, good compatibility with reservoir rocks and formation water at high temperature.
\end{abstract}

Keywords: Formate; Drilling and Completion Fluid System; Solid Free System; Hydrocarbon Reservoir Protection

\section{INTRODUCTION}

Formate drilling and completion fluid is a new type of clean brine system which has been developed from inorganic salt brine drilling fluid system. Currently there are mainly three kinds of formate: sodium formate, potassium formate and cesium formate. Compared with conventional drilling fluid, formate drilling fluid is characterized by no bentonite slurry. It is the theoretical foun- dation that formate drilling fluid can achieve strong inhibitory, and it is also the key to being better than conventional water base drilling fluid. Some scholars have studied this before, such as Liuyu has published a paper of "Researches and uses of solids-free high density formate and high temperature crosslinking water base systems as drill-in fluid" in 2005. Then he has applied the drilling fluid into Liaohe Oilfield and the petroleumin-place has been increased. Wang Yongsheng has studied the application effect of the formate drilling fluid in Yingtai gas field in 2012. And this drilling fluid system has helped to protect the reservoir and save the exploration cost. Based on the previous research, this paper is studied for some new findings and applications [1].

\section{THE BASIC NATURE OF FORMATE}

Formate has the characteristics of high solubility, high density, high $\mathrm{pH}$ value, low crystallization point. With the increase of alkali metal atomic weight, saturation concentration, saturation density and $\mathrm{pH}$ value become higher, and crystallization point becomes lower.

Through indoor study, the following features of formate have been found:

1) There is the function of stabilizing shale. Shale is equivalent to the selective semi-permeable membrane in the non fractured low permeability shale formation $(\mathrm{K} \leq$ $10 \times 10^{-3} \mu \mathrm{m}^{2}$ ). In the high concentration brine, due to the low water activity, the osmotic pressure can promote the shale pore water reflux. This reflux will make formation stress and effective stress of near wellbore zone increase to stabilize borehole wall.

2) Formate has a good compatibility with the oilfield commonly used polymer, and can slow the speed of hydrolysis and oxidation degradation of many thickeners and filtrate reducers under high temperature and pressure. 


\section{DETERMINING THE FORMATE DRILLING FLUID FORMULATION}

\subsection{Optimization of Filtrate Reducer}

The base slurry: $500 \mathrm{ml}$ Water $+80 \%$ Sodium formate.

For the drilling and completion fluid system, filtration index of effective control system is crucial. We select TJ1 for the filtrate reducer. And experiments that addition amount of TJ-1 is different are conducted. Results are shown in Table 1.

According to the experimental data in the table, when addition amount of TJ-1 is 3\%, instantaneous water loss is small, and drilling preliminary requirements can be satisfied. Combining with the actual use situation, the TJ-1 that its addition amount is $3 \%$ is selected for the filtrate reducer.

\subsection{Optimization of Oil Layer Protective Agent}

In order to further improve the comprehensive ability of reduction in water loss of system and reduce the damage of oil and gas layer, we select the optimum oil layer protective agent in the laboratory. Experimental results are shown in Table 2.

According to the data in the table, by optimizing, TJ-1 plus JYW-3 can reduce water loss greatly after $150^{\circ} \mathrm{C}$ high temperature hot rolling. So JYW-3 that its addition amount is $3 \%$ is selected for the oil layer protective agent.

\subsection{Optimization of Tackifier}

Because the viscosity of formate fluid can not meet needs of drilling fluid viscosity in practical application, proper tackifier must be added in drilling fluid. We had carried on the contrast experiment to select tackifier. The results are shown in Table 3.

Formula 1: The base slurry $+3 \%$ TJ-1 $+0.5 \%$ TXZ-1 $+3 \%$ JYW-3;

Table 1. Optimization experiment of filtrate reducer.

\begin{tabular}{ccccccc}
\hline Formula & $\varphi 600$ & $\varphi 300$ & $\varphi 6$ & $\varphi 3$ & Gel pa/pa & API ml \\
\hline $\begin{array}{c}\text { The base slurry } \\
+1 \% \text { TJ-1 }\end{array}$ & 25 & 13 & 0 & 0 & $0 / 0.5$ & - \\
$\begin{array}{c}\text { The base slurry } \\
+2 \% \text { TJ-1 } \\
\begin{array}{c}\text { The base slurry } \\
+3 \% \text { TJ-1 }\end{array}\end{array}$ & 32 & 18 & 1 & 1 & $0.5 / 0.5$ & $18(18)$ \\
\hline
\end{tabular}

Table 2. Optimization experiment of oil layer protective agent.

\begin{tabular}{cccccccc}
\hline Formula & $\varphi 600$ & $\varphi 300$ & $\varphi 6$ & $\varphi 3$ & $\mathrm{Gel} \mathrm{pa} / \mathrm{pa}$ & YP Pa & API ml \\
\hline Formula 1 & 113 & 64 & 8 & 6 & $2 / 2.5$ & 7.5 & 23.5 \\
Formula 2 & 187 & 117 & 6 & 4 & $2 / 2.5$ & 23.5 & 6.5 \\
Formula 3 & 141 & 81 & 3 & 2 & $0.5 / 1$ & 10.5 & 2.6 \\
\hline
\end{tabular}

Note: Test conditions of $150^{\circ} \mathrm{C}$, hot rolling for $16 \mathrm{~h}$.
Table 3. Optimization experiment of tackifier.

\begin{tabular}{ccccccc}
\hline Formula & $\varphi 600$ & $\varphi 300$ & $\varphi 6$ & $\varphi 3$ & $\mathrm{Gel} \mathrm{pa} / \mathrm{pa}$ & API ml \\
\hline Formula 1 & 29 & 15 & 0 & 0 & $0 / 0$ & 16.5 \\
Formula 2 & 99 & 74 & 17 & 12 & $1.5 / 2.5$ & 8 \\
Formula 3 & 32 & 17 & 0 & 0 & $0 / 0$ & 14 \\
\hline
\end{tabular}

Note: Test conditions of $180^{\circ} \mathrm{C}$, hot rolling for $16 \mathrm{~h}$.

Formula 2: The base slurry $+3 \% \mathrm{TJ}-1+0.5 \%$ TXZ-2 $+3 \% \mathrm{JYW}-3$;

Formula 3: The base slurry $+3 \% \mathrm{TJ}-1+0.5 \% 80 \mathrm{~A} 51$ $+3 \% \mathrm{JYW}-3$.

By experimental contrast, we know that TXZ-2 has good viscosifying action and resistance to high temperature. So TXZ-2 that its addition amount is $0.5 \%$ is selected for the tackifier [2].

Through the above research, finally, the overall formula of the formate clay free drilling and completion fluid system was determined for: water $+80 \%$ sodium formate $+3 \% \mathrm{TJ}-1+0.5 \% \mathrm{TXZ}-2+3 \% \mathrm{JYW}-3$.

\section{PEFORMANCE EVALUATION OF FORMATE DRILLING FLUID SYSTEM}

\subsection{Rheological Properties Evaluation}

Drilling fluid rheological property is usually described with rheological curve, plastic viscosity (PV), yield point (YP), gel strength (Gel), apparent viscosity (AV) and other rheological parameters of drilling fluid.

According to the experimental data in Table 4, when the aging temperature is below $150^{\circ} \mathrm{C}$, rheological property and building capacity of drilling fluid are stable, the change is not big. When the aging temperature is higher than $150^{\circ} \mathrm{C}$, filtration of system increases by much, and rheological property and building capacity of system become bad. So temperature resistance capacity of formate drilling fluid system can reach $150^{\circ} \mathrm{C}$.

\subsection{Pollution Resistance Experiment}

In drilling process, soluble salt and clay which are the main pollution sources can affect the rheological property and filtration property of drilling fluid system. In view of this, the capacity of soil penetration resistance and soluble salt pollution resistance of the formate drilling fluid system was evaluated. The results are shown in Table 5.

According to Table 5, after formate drilling fluid was $16 \mathrm{~h}$ under high temperature $150^{\circ} \mathrm{C}$, in the drilling fluid system which added soil powder, its plastic viscosity, yield point and API filtration quantity increased. And after being polluted with soluble salt, its plastic viscosity reduced, yield point and API filtration quantity increased. Changes are within the acceptable range [3]. 
Table 4. Rheological properties of formate drilling fluid under high temperature.

\begin{tabular}{cccccc}
\hline \multirow{2}{*}{ Conditions } & \multicolumn{3}{c}{ Rheological parameters } & \multirow{2}{*}{ API FL } & PH \\
\cline { 2 - 4 } & $\mathrm{PV} \mathrm{(mPa} \cdot \mathrm{s})$ & $\mathrm{YP}(\mathrm{Pa})$ & $\mathrm{Gel} \mathrm{pa} / \mathrm{pa}$ & $\mathrm{ml}$ & \\
\hline $\begin{array}{c}\text { Before the high } \\
\text { temperature }\end{array}$ & 32 & 7.0 & $1 / 2$ & 0.8 & 9 \\
$120^{\circ} \mathrm{C} / 16 \mathrm{~h}$ & 31 & 7.0 & $1 / 2$ & 1.1 & 9 \\
$150^{\circ} \mathrm{C} / 16 \mathrm{~h}$ & 29 & 6.5 & $1 / 2$ & 1.6 & 9 \\
$180^{\circ} \mathrm{C} / 16 \mathrm{~h}$ & 25 & 3.5 & $1.5 / 2.5$ & 8 & 9 \\
\hline
\end{tabular}

Table 5. Anti pollution experimental results under high temperature.

\begin{tabular}{cccc}
\hline Formula & PV mPa's & YP Pa & API Fl ml \\
\hline 1\#: The base slurry + 3\% TJ-1 & 29 & 6.5 & 1.6 \\
$0.5 \%$ TXZ-1 + 3\% JYW-3 & & 16 & 3.5 \\
2\#: $1 \#+5 \%$ bentonite & 44 & 7 & 3.4 \\
3\#: $1 \#+6 \% \mathrm{CaCl}_{2}$ & 23 & 7
\end{tabular}

Note: Test conditions of $150^{\circ} \mathrm{C}$, hot rolling for $16 \mathrm{~h}$.

\subsection{Inhibitory Experiment}

The linear expansion rate of shale in drilling fluid system is tested to obtain the ability of system to inhibit shale swelling. The experimental results are shown in Tables 6 and 7.

According to experimental data, we can see that formate clay free drilling and completion fluid is superior to the polymer drilling fluid and similar to oil-in-water drilling fluid in inhibiting clay hydration expansion ability. It has a good ability that hydration expansion of mineral composition such as the shale is prevented to avoid dispersion and migration of micro-sized particles.

Rolling recovery rate of the shale is used to describe inhibition dispersion capacity of drilling fluid system to shale [4].

Shale recovery experiment results show that optimal formate clay free drilling and completion fluid system is superior to the polymer drilling fluid and similar to oilin-water drilling fluid in inhibiting clay dispersibility. It can effectively inhibit clay dispersion and has a good stability in shale.

\subsection{Compatibility Experiment}

$350 \mathrm{ml}$ drilling fluid mixed with $50 \mathrm{~g}$ reservoir rock debris, then hot rolled $16 \mathrm{~h}$ under $120^{\circ} \mathrm{C}$. Rock debris recovery rate was $98.5 \%$, the shape and size of rock debris were little changed. It shows that the drilling fluid has good compatibility with reservoir rocks.

Formate drilling and completion fluid filtrate mixed with the certain proportion simulation formation water. Then we used the method for the visual and flocculation to evaluate the compatibility of drilling fluid and formation water. It can be seen that chemical reaction and
Table 6. Swelling experiment results.

\begin{tabular}{ccccc}
\hline Type & $30 \mathrm{~min}$ & $1 \mathrm{~h}$ & $2 \mathrm{~h}$ & $3 \mathrm{~h}$ \\
\hline Oil-in-water drilling fluid & 0 & 0.01 & 0.02 & 0.03 \\
Formate drilling fluid & 0.01 & 0.02 & 0.03 & 0.04 \\
Polymer drilling fluid & 0.07 & 0.09 & 0.11 & 0.11 \\
\hline
\end{tabular}

Table 7. Rolling recovery experiment results.

\begin{tabular}{cccc}
\hline Type & 10 mesh & 20 mesh & 30 mesh \\
\hline Oil-in-water drilling fluid & $97.3 \%$ & $99.3 \%$ & $99.7 \%$ \\
Formate drilling fluid & $97 \%$ & $98.7 \%$ & $99.3 \%$ \\
Polymer drilling fluid & $70.7 \%$ & $79.3 \%$ & $80 \%$ \\
\hline
\end{tabular}

sediment were not generated between drilling fluid filtrate and simulation formation water. It shows that formate drilling and completion fluid has good compatibility with reservoir fluid.

\subsection{Lubricity Experiment}

Lubricity evaluation needs three main parameters, the drilling fluid lubrication coefficient $\mathrm{K}$, the extreme pressure film strength $\mathrm{P}$ and mud cake friction coefficient $\mathrm{K}_{\mathrm{f}}$. Evaluation data and the results are shown in Table 8.

According to the above table, the lubrication performance of system is good. It provides a powerful guarantee in order to decrease the friction torque of drill tool. The drilling fluid can fully meet the needs of the deep drilling as long as strengthening solid phase control.

\section{CONCLUSIONS}

The formate drilling and completion fluid system has been applied to the deep well of Lungu area in Tarim. Through the field experimentation, some new and good performance of the formate drilling fluid can be found out. The formate drilling fluid is of good rejection capability and shale stability. In the conditions of low viscosity, the shear thinning and capability of bringing cuttings of the formate drilling fluid are also excellent. It can meet the drilling requirements. As the formate drilling fluid is of low density and no solid phase, it helps to find problems in time so as to protect reservoir. The formate drilling fluid system has removed the damage caused by the solid particles, which block the hydrocarbon reservoir. At the same time, the compatibility between the formate and common treating agents of oil field is fine. Therefore, the operating temperature of $\mathrm{CMC}$ and biopolymer can be enhanced to $140^{\circ} \mathrm{C}$. According to the experimental results, it can be concluded as follows.

1) It uses single treatment agent optimization experiment such as the optimization of filtrate reducer, oil layer protective agent and tackifier in laboratory. Finally, the 
Table 8. Unctuosity evaluation results.

\begin{tabular}{ccccc}
\hline System & $\mathrm{K}$ & $\mathrm{K}_{\mathrm{f}}$ & $\mathrm{P}\left(\right.$ pound $\left./ \mathrm{cun}^{2}\right)$ \\
\hline Formate system & 0.15 & 0.0602 & 47,360 \\
Formate system + 20\% Drilling cuttings & 0.19 & 0.0730 & 39,520 \\
\hline
\end{tabular}

overall formula of the formate clay free drilling and completion fluid system was determined for: water $+80 \%$ sodium formate $+3 \%$ TJ- $1+0.5 \%$ TXZ- $2+3 \%$ JYW- 3 .

2) Indoor evaluation experiments show that the formate drilling and well completion fluid system has good rheological property, pollution resistance and reservoir protection performance in the heat. At the same time, filter loss is low, inhibition ability is strong, high temperature resistance reaches $150^{\circ} \mathrm{C}$, lubrication performance is fine, and there is good compatibility with the reservoir rock and formation water.

\section{REFERENCES}

[1] Gao, P. and Yin, D. (2006) Simulation study on the conditions of converting injection wells to production wells in low permeability reservoirs. Journal of Daqing Petroleum Institute, 6, 12-22.

[2] Wang, W., Pu, H., Yin, D. and Gao, P. (2006) The study on reasonable infilling method for low permeability reservoir. Small Hydrocarbon Reservoirs, 12, 298-310.

[3] Gao, P. and Towler, B. (2010) Strategies for evaluation of the $\mathrm{CO}_{2}$ miscible flooding process. SPE-138786, Conference of 2010 Abu Dhabi International Petroleum Exhibition, Abu Dhabi, 1-4 November 2010, 10 p.

[4] Gao, P., Towler, B. and Jiang, H. (2010) Feasibility investigation of $\mathrm{CO}_{2}$ miscible flooding in south slattery minnelusa reservoir, Wyoming. SPE-133598, 2010 SPE Western North American Regional Meeting, 27-29 May 2010, Anaheim, 4-14. 